\title{
High Working Memory Load Increases Intracortical Inhibition in Primary Motor Cortex and Diminishes the Motor Affordance Effect
}

\author{
Scott M. Freeman, ${ }^{1}$ Sirawaj Itthipuripat, ${ }^{2}$ and Adam R. Aron ${ }^{1,2}$ \\ ${ }^{1}$ Department of Psychology and ${ }^{2}$ Neurosciences Program, University of California-San Diego, La Jolla, California 92093
}

\begin{abstract}
Motor affordances occur when the visual properties of an object elicit behaviorally relevant motor representations. Typically, motor affordances only produce subtle effects on response time or on motor activity indexed by neuroimaging/neuroelectrophysiology, but sometimes they can trigger action itself. This is apparent in "utilization behavior," where individuals with frontal cortex damage inappropriately grasp affording objects. This raises the possibility that, in healthy-functioning individuals, frontal cortex helps ensure that irrelevant affordance provocations remain below the threshold for actual movement. In Experiment 1, we tested this "frontal control" hypothesis by "loading" the frontal cortex with an effortful working memory (WM) task (which ostensibly consumes frontal resources) and examined whether this increased EEG measures of motor affordances to irrelevant affording objects. Under low WM load, there were typical motor affordance signatures: an event-related desynchronization in the mu frequency and an increased P300 amplitude for affording (vs nonaffording) objects over centroparietal electrodes. Contrary to our prediction, however, these affordance measures were diminished under high WM load. In Experiment 2, we tested competing mechanisms responsible for the diminished affordance in Experiment 1 . We used paired-pulse transcranial magnetic stimulation over primary motor cortex to measure long-interval cortical inhibition. We found greater long-interval cortical inhibition for high versus low load both before and after the affording object, suggesting that a tonic inhibition state in primary motor cortex could prevent the affordance from provoking the motor system. Overall, our results suggest that a high WM load "sets" the motor system into a suppressed state that mitigates motor affordances.
\end{abstract}

Key words: EEG; GABA; inhibition; motor affordance; working memory

Significance Statement

Is an irrelevant motor affordance more likely to be triggered when you are under low or high cognitive load? We examined this using physiological measures of the motor affordance while working memory load was varied. We observed a typical motor affordance signature when working memory load was low; however, it was abolished when load was high. Further, there was increased intracortical inhibition in primary motor cortex under high working memory load. This suggests that being in a state of high cognitive load "sets" the motor system to be imperturbable to distracting motor influences. This makes a novel link between working memory load and the balance of excitatory/inhibitory activity in the motor cortex and potentially has implications for disorders of impulsivity.

\section{Introduction}

Motor affordances occur when the visual properties of an object elicit behaviorally relevant motor representations (Gibson,

Received Jan. 26, 2016; revised March 23, 2016; accepted April 9, 2016.

Author contributions: S.M.F. and A.R.A. designed research; S.M.F. performed research; S.I. contributed unpublished reagents/analytic tools; S.M.F. and S.I. analyzed data; S.M.F., S.I., and A.R.A. wrote the paper.

This work was supported by National Institutes of Health Grant DA026452 and James S. McDonnel Scholar Award 220020375 to A.R.A. and National Science Foundation Graduate Research Fellowship to S.M.F. We thank Cathy Stinear for advice with the LICI procedure and Lucia Riggio for the cup stimuli.

The authors declare no competing financial interests.

Correspondence should be addressed to Dr. Adam R. Aron, Department of Psychology, University of California-

San Diego, 9500 Gilman Drive, La Jolla CA 92093. E-mail: adamaron@ucsd.edu.
1979). For example, viewing a right-facing cup handle activates left hemisphere motor areas (Grafton et al., 1997; Chao and Martin, 2000), resulting in potentiation of the right hand (McBride et al., 2012). Such motor potentiation from affording (vs nonaffording) objects has been observed using a range of methods. These include the following: shorter reaction times (RTs) when the orientation of a handle is compatible with the responding hand (Tucker and Ellis, 1998, 2004), increased BOLD signal in premotor cortex when viewing graspable objects (Grafton et al., 
1997; Chao and Martin, 2000), greater motor excitability in the affording effector (measured as motor evoked potentials [MEPs]) (Buccino et al., 2009; Franca et al., 2012), greater mu frequency $(7.5-12.5 \mathrm{~Hz})$ event-related desynchronization (ERD) over centroparietal electrodes (Muthukumaraswamy et al., 2004; Proverbio, 2012), and higher amplitude in a late positive eventrelated potential (ERP) called the P300 (Proverbio et al., 2011; Righi et al., 2014).

Notably, motor affordances appear to occur automatically, as response-compatibility effects are found even when the objects are irrelevant to the task (Ellis and Tucker, 2000; Fischer and Dahl, 2007) and when attention is focused away from the object (Riggio et al., 2008). This automatic motor potentiation could have functional benefits for behavior by facilitating more efficient use of objects that entail action requirements (Handy et al., 2003; Tucker and Ellis, 2004). However, when the affording object is irrelevant to the task, such motor potentiation could be maladaptive by provoking automatic action tendencies that are incongruent with task goals. In line with this, inappropriate reaching and grasping of affording objects have been observed in patients with frontal lobe damage, i.e., so-called "utilization behavior" (Lhermitte, 1983; Shallice et al., 1989; Archibald et al., 2001; Besnard et al., 2010). This raises the possibility that, in healthy-functioning individuals, frontal cortex helps ensure that motor activity elicited by irrelevant affording objects remains below the threshold for actual movement (Schaefer et al., 2010; McBride et al., 2012, 2013).

In Experiment 1, we tested this "frontal control" hypothesis by "loading" frontal resources with an effortful working memory (WM) task (Mitchell et al., 2002; Kim et al., 2005; Owen et al., 2005). Specifically, we presented affording and nonaffording objects while participants were under high (effortful) or low (noneffortful) WM load. We indexed motor affordances with the well-established electroencephalographic (EEG) signatures of mu ERD and the P300 ERP component over centroparietal electrodes (Pfurtscheller and Neuper, 1997; McFarland et al., 2000; Righi et al., 2014). In accordance with the frontal control hypothesis, we predicted increased affordance effects for the mu ERD and P300 ERP component during high WM load, as fewer resources would be available to control task-irrelevant motor provocations. Following Experiment 1's results, we conducted a second experiment to try to better understand how WM load and the affordance are related.

\section{Materials and Methods}

\section{Experiment 1}

Participants. Seventeen right-handed, neurologically intact human volunteers (11 females) with normal or corrected-to-normal vision were recruited from the University of California, San Diego (mean \pm SD age, $21 \pm 3.3$ years). Each participant provided written informed consent as required by the local Institutional Review Board at University of California-San Diego. They were compensated $\$ 15$ per hour. Following preprocessing, data from 3 participants still contained substantial blink, eye movement, and head movement artifacts that resulted in systematic noise across all electrodes, rendering their data unanalyzable. We therefore excluded the 3 participants, which left the data from 14 participants in the final behavioral and EEG analyses. Right-handedness was determined by participants' self-report before arriving and upon arrival.

Behavioral task. Stimuli were presented on a PC running Windows XP using MATLAB (The MathWorks) and the Psychophysics Toolbox (version 3.0.8). Participants were seated $60 \mathrm{~cm}$ from the CRT monitor with a white background ( $60 \mathrm{~Hz}$ refresh rate) in a sound-attenuated and electromagnetically shielded room (ETS Lindgren).

The experiment was divided into two stages: the capacity test, followed by the experiment proper. The purpose of the capacity test was to provide an estimate of WM capacity for the high WM load condition in the experiment proper. In the capacity test, each trial began with a fixation cross for a variable intertrial interval period of $2-5 \mathrm{~s}$. Then, a string of black uppercase letters in Arial font appeared at the center of a white screen. The string of letters always consisted of 6, 7, 8, or 9 letters. All letters were chosen randomly from an alphabetic list that excluded only vowels. These letters remained on the screen for $4.5 \mathrm{~s}$. During this time, the word "Memorize" was presented in red color at the top of the screen, as participants were instructed to do their best to read the letters on the screen and hold those letters in WM. After the $4.5 \mathrm{~s}$ Memorize phase, there was a $1.875 \mathrm{~s}$ interstimulus interval (ISI) before participants were tested on the string of letters. During this period, participants were encouraged to rehearse the letter strings during the retention interval. Next, participants were probed with another letter string to evaluate their performance on the WM task. The probe letter string either identically matched the letters presented in the Memorize phase, or differed such that (only) two adjacent letters switched positions. Thus, the Probe phase always consisted of the same letters as in the Memorize phase, with the only possible change being a switch of two adjacent letters in the string. During the Probe phase, the words "Same or Different?" were displayed at the top of the screen in red. Moreover, the letter string in the probe phase was presented in lowercase Times font to reduce the likelihood that participants could rely on familiarity of the letter string instead of WM. The Probe phase lasted for a maximum of $3.75 \mathrm{~s}$, and participants were instructed to respond both as quickly and as accurately as possible by pressing a keypad button with the right middle finger for "same" and the right index finger for "different." The actual probability of the Probe letter string matching the Memorize letter string was 0.5 . There were two blocks of 30 trials in the capacity test phase (60 trials total). The string lengths used $(6,7,8$, and 9$)$ were each presented 15 times. EEG data were not recorded during the capacity test.

Following the capacity test, we plotted the percentage correct (of 15) for each string length and chose the string length that was closest to a 75\% correct for the experiment proper (50\% correct is chance). This allowed the following: (1) relatively equal high load difficulty and performance across participants; (2) a moderate level of high WM load difficulty that was above chance, yet also taxed WM resources; and (3) a single high WM load string length for each individual, which helped avoid potential confounds of different letter string lengths in the analysis stage.

Next, the experiment proper stage began (Fig. 1). This stage was very similar to the capacity test, but with several key differences. First, on any given trial, the letter string in the Memorize phase consisted of either two letters (low load) or the high WM load string length chosen from the capacity test (i.e., 6, 7, 8, or 9 letters). Regardless of letter string length, participants were given $4.5 \mathrm{~s}$ to memorize the string. Second, on $80 \%$ of the trials, either an image of a right-handled cup (affording object) or an urn (nonaffording control object) was presented for $750 \mathrm{~ms}$ in the center of the screen. The cups used here were used in a previous TMS-EMG experiment that showed an affordance effect via greater MEPs when viewing the cups versus control objects (Buccino et al., 2009). Moreover, the same cups were used in a pilot TMS-EMG experiment we conducted that measured irrelevant affordances in a target detection task and found a significant affordance effect (S.M.F. and A.R.A., unpublished observations). Together, this increased our confidence that viewing the cups potentiated motor activation and thus was sufficiently affording. As for the control objects, urns were chosen to match the physical properties of the cups as best as we could, without the control object having a strong affordance, at least compared with the handled cups. The presentation of the stimulus objects occurred at a variable ISI of $0.75,1.5,2.25$, or $3 \mathrm{~s}$ (occurring with an equal probability) following the Memorize phase. The purpose of the variable ISI times was to make the appearance of the object unpredictable, thus helping ensure that the participant did not avert attention away from the screen. Note that we could not include ISI as part of the statistical analysis because trials numbers would be far too low $(<10$ trials) for each condition. The images of the cup and urn were randomly selected from a set of five possible images for each object type, and each object had a visual angle of $\sim 6.2^{\circ} \times 6.2^{\circ}$. The total ISI between the Memorize and Probe phases remained constant at $4.5 \mathrm{~s}$. A third difference was that, on $20 \%$ of trials (called catch trials), no object image 
was presented and the Probe phase occurred in its place. This ensured that participants maintained their attentional focus because they were instructed to respond as quickly and accurately as possible. Finally, the experiment proper had 5 blocks with 40 trials per block (200 total trials). In each block, there were 8 trials per experimental condition (low load affording [low-afford], low load control [low-control], high load affording [high-afford], high load control [high-control]), as well as 4 low load catch trials and 4 high load catch trials per block. Across the entire experiment, this yielded 40 total trials per experimental condition. As in the capacity test phase, the actual probability of the Probe letter string matching the Memorize phase was 0.5.

EEG recording. The continuous EEG data were recorded using a 64 electrode Biosemi ActiveTwo system (Biosemi Instrumentation) at a sampling rate of $512 \mathrm{~Hz}$. The elastic EEG cap covered the head from above the eyebrows to below the inion and the 64 electrodes were equally spaced across the EEG cap. The central electrode $\mathrm{Cz}$ was placed right above the vertex located halfway between the nasion and the inion and between the left and right ears. Two additional electrodes were placed at the left and right mastoids, as reference electrodes. Blinks and vertical eye movements were monitored via four extra electrodes placed below and above the eyes. Horizontal eye movements were monitored by another pair of electrodes, placed laterally near the outer canthi of the left and right eyes. The EEG data were referenced on-line to the common mode sense active electrodes/driven right leg passive electrodes and all offsets from the reference were maintained $<20 \mu \mathrm{V}$.

EEG preprocessing. We used EEGlab11.0.3.1b (Delorme and Makeig, 2004) and custom MATLAB scripts to preprocess the EEG data offline. First, we re-referenced the continuous EEG data to the mean of the two mastoid electrodes and applied $0.25-\mathrm{Hz}$ high-pass and $55-\mathrm{Hz}$ low-pass Butterworth filters (3rd order). Then, we rejected prominent eye blink artifacts using independent components analysis from the continuous EEG data (Makeig et al., 1996). Next, the continuous data were segmented into epochs extending from-976 ms before the onset of the object to the end of the trial. Finally, we disregarded epochs contaminated by residual eye blinks, eye movements, excessive muscle activity, or slow-going drifts using threshold rejection and visual inspection $(9.62 \% \pm 1.4 \%$ of trials were rejected).

EEG frequency analysis. To examine differences in mu amplitudes across experimental conditions, we filtered the epoched EEG data using the complex Morlet function in MATLAB (cmor5-3). We then focused on the mu frequency band, which ranges from $\sim 7$ to $13 \mathrm{~Hz}$ (Arroyo et al., 1993; Pfurtscheller and Lopes da Silva, 1999; Wang et al., 1999). Notably, previous studies have shown that lower $(\sim 8-10 \mathrm{~Hz})$ versus upper $(\sim 10-12 \mathrm{~Hz})$ frequency bands in the mu range likely correspond to different sensorimotor mechanisms (Pfurtscheller, 2003; Pfurtscheller et al., 2006; Proverbio, 2012; Rüther et al., 2014). We therefore analyzed lower and upper mu rhythms separately, with a frequency range of 7-10 $\mathrm{Hz}$ and $10-13 \mathrm{~Hz}$ for low and high mu rhythms, respectively (we used a slightly broader range than previous studies to capture all possible mu- related activity). Based upon a recent study that analyzed affordances based on lower and upper mu frequency bands (Ruther et al., 2014), we expected the affordance to take place in the lower mu frequency range.

We investigated mu ERD in three selected centroparietal electrodes $(\mathrm{Cz}, \mathrm{CPz}, \mathrm{Pz})$, which was based on the topographic maps of past studies that found mu ERD motor affordance effects (Proverbio, 2012; Kumar et al., 2013). These studies tended to show affordance-related ERD at more midline and posterior sensorimotor areas than classic ERD studies examining actual and planned movements (Pfurtscheller and Aranibar, 1979; McFarland et al., 2000). To test for mu amplitude differences, we focused on a relatively broad time window of 100-750 ms after the onset of the object. We tested for mu amplitude differences in lower and upper mu frequency bands separately using two-way repeated-measures 
ANOVAs with factors of Load (high/low) and Object (affording/control). The ANOVAs were followed by planned contrasts to examine potential differences in the affording versus control object for both high and low load.

In addition, past studies have shown that frontal theta activity $(\sim 4-7$ $\mathrm{Hz}$ ) is an index of the involvement of frontal cortex in WM processes, including the maintenance and manipulation of WM contents (Gevins et al., 1997; Jensen and Tesche, 2002; Onton et al., 2005; Pesonen et al., 2007; Mizuhara and Yamaguchi, 2011; Itthipuripat et al., 2013; Hsieh and Ranganath, 2014). In general, it has been shown that frontal theta activity increases with WM load (Gevins et al., 1997; Jensen and Tesche, 2002; Onton et al., 2005; Pesonen et al., 2007). Thus, to confirm that our task manipulation successfully manipulated WM load, we analyzed frontal theta activity in the low and high load conditions over midline electrodes (AFz, Fz, and $\mathrm{FCz}$ ). We filtered the data from 4 to $7 \mathrm{~Hz}$ (with the same procedure as mu ERD), and compared differences in theta amplitude across high and low load conditions from $-750-0 \mathrm{~ms}$ before the onset of the object (without baseline correction). We then used a paired $t$ test to analyze potential differences between high and low load.

ERP analysis. In addition to the EEG frequency analysis, we compared amplitude differences of ERPs across all experimental conditions. To do so, we first subtracted the $-100-0 \mathrm{~ms}$ pre-object baseline from the artifact-free epoched data and computed the average of the object stimulus-locked EEG data for each participant using a standard averaging procedure (Luck, 2005). Then, we averaged the data across all participants to obtain the grand-average ERPs for low-afford, low-control, high-afford, and high-control conditions. In this analysis, we focused on the following: (1) the early positive potential P1 (peaking at 90 to $120 \mathrm{~ms}$ in left and right posterior-occiptal electrodes; i.e., O1, PO3, PO7 for left and $\mathrm{O} 2, \mathrm{PO} 4, \mathrm{PO} 8$ for right) to confirm that there were no general perceptual difference in object processing across WM load conditions; and (2) the later positive potential P300 (peaking at 300 to $500 \mathrm{~ms}$ at the centroparietal electrodes; i.e., $\mathrm{Cz}, \mathrm{CPz}, \mathrm{Pz}$ ) because past studies have found higher $\mathrm{P} 300$ amplitude for affording versus nonaffording stimuli (Proverbio et al., 2011; Righi et al., 2014). For the P100 analysis, we used a three-way repeated-measures ANOVA to compare mean amplitude differences for the factors of Load (high/low), Object (affording/control), and Hemisphere (right/left) because early visual processing of the right-handled cup was likely to show hemispheric differences. For the P300 analysis, we used a two-way repeated-measures ANOVA to compare mean amplitude difference for the factors of Load (high/low) and Object (affording/control) in the midline centroparietal electrodes.

\section{Experiment 2}

We used long-interval paired-pulse transcranial magnetic stimulation ( ppTMS) over primary motor cortex (Nakamura et al., 1997; Chen et al., 1999; McDonnell et al., 2006). This method lets one measure longinterval cortical inhibition (LICI). LICI has been shown to relate to gamma-aminobutyric acid-B $\left(\mathrm{GABA}_{\mathrm{B}}\right)$ tone in primary motor cortex (McDonnell et al., 2006; Kohl and Paulsen, 2010). To measure LICI, one compares the amplitude of the MEP from a single test pulse with the amplitude of a test pulse that is preceded by a conditioning pulse, typically 50-200 ms earlier. The conditioning pulse putatively activates $\mathrm{GABA}_{\mathrm{B}}$ interneurons, and this attenuates the amplitude of the test pulse, compared with the nonconditioned test pulse.

Participants. Twenty right-handed, neurologically intact human volunteers ( 8 females) with normal or corrected-to-normal vision were recruited from the University of California, San Diego (mean \pm SD age, $20.5 \pm 1.7$ years). Each participant provided written informed consent as required by the local Institutional Review Board at University of California-San Diego. They were compensated $\$ 15$ per hour. Four subjects were excused before participating in the experiment proper because there was excessive EMG noise (specifically, EMG values consistently exceeded our cutoff criterion of $0.01 \mathrm{mV}$ ) during threshholding and in the intertrial baseline during the capacity test. It was later determined that this related to an equipment malfunction that was subsequently fixed. This left data from 16 participants in the final behavioral and TMS analyses.
Behavioral task. The behavioral task was almost identical to the design in Experiment 1, with a few small exceptions to adjust for the ppTMS method used in Experiment 2. First, instead of 5 total blocks in the experiment proper, there were now 6 blocks to allow for more TMS pulses. Second, the total ISI between the Memorize and Probe phases remained constant at $4.0 \mathrm{~s}$ (instead of $4.5 \mathrm{~s}$ ) to allow for more trials. Third, instead of making a button press with the right hand, participants were instructed to respond verbally into a microphone by saying "true" if they thought that the trial was a match and to not respond at all if they thought that it was not a match. This helped avoid any possible contamination of the electromyography (EMG) signal due to preparatory hand movement and minimized the amount of action required on a given trial. To determine whether a response was made, audio files from each trial were analyzed via visual inspection for both amplitude and shape of the response.

Paired-pulse TMS procedure details. TMS pulses were generated with a MagStim 20-2 monophasic stimulator connected to a MagStim BiStim module (Magstim) and a $70 \mathrm{~mm}$ figure-of-eight coil. Surface EMG was recorded from the first dorsal interosseous muscle of the right hand via $10 \mathrm{~mm}$-diameter $\mathrm{Ag}-\mathrm{AgCl}$ hydrogel electrodes (Medical Supplies).

The coil was placed $5 \mathrm{~cm}$ lateral and $2 \mathrm{~cm}$ anterior to the vertex and repositioned while delivering a TMS stimulus to locate the position where the largest MEPs were observed consistently. The maximum MEP size was determined by increasing TMS stimulus intensity in 3\%-4\% increments until the MEP amplitude no longer increased. Then, the TMS stimulus intensity was adjusted to produce MEPs that were approximately half of the maximum MEP amplitude while the participant was at rest. Once a half-maximum TMS stimulus intensity was established, ppTMS was applied while the participant was at rest, such that TMS pulses alternated between paired and single pulses (note that TMS stimulus intensity is the same for both pulses). All paired pulses throughout the experiment were delivered at a $100 \mathrm{~ms}$ ISI, which is an effective ISI to evoke LICI that reflects supraspinal inhibition in the motor cortex (Nakamura et al., 1997; Chen et al., 1999; McDonnell et al., 2006; Chu et al., 2008). The TMS stimulus intensity was adjusted until it was verified that (1) the nonconditioned pulse (NP) continued to elicit half-maximum MEP amplitudes and (2) the test pulse (TP) elicited a 50\% inhibition. This procedure was then repeated during the capacity test to confirm that the TMS stimulus intensity continued to meet the above criteria in a task setting. The mean TMS stimulus intensity across participants was $51.9 \pm$ $9.6 \%$ stimulator output. An examination of the root mean square values for the $100 \mathrm{~ms}$ time window before the TMS pulse showed no significant main effects or interactions (all $p$ values $>0.34$ ), demonstrating that the MEP patterns described below were not contaminated by differences in the pre-TMS period.

During the experiment proper, single and paired-pulse trials were presented randomly to avoid predictions regarding pulse type. The pulse was delivered either before or after the onset of the object. To reduce predictability of the pulse timing, the pulse was presented either 300 or $500 \mathrm{~ms}$ before or after the object onset. All trials types were fully counterbalanced within each experimental block.

LICI analysis. An EMG sweep started $200 \mathrm{~ms}$ before stimulation. MEPs were identified from the EMG using in-house software developed in MATLAB (The MathWorks). To ensure participants were at rest before the MEP, trials were excluded if the root mean square EMG in the $100 \mathrm{~ms}$ before the TMS pulse was $>0.01 \mathrm{mV}$. To ensure an MEP was generated on a given trial, trials were excluded if the MEP of the NP was $<0.05 \mathrm{mV}$ (during single-pulse trials) or if the MEP of both the conditioning pulse and the TP were $<0.05 \mathrm{mV}$ (during paired-pulse trials). Finally, we also excluded trials if the amplitude maxed out at $1 \mathrm{mV}$ or $-1 \mathrm{mV}$ because we used a CED MICRO 1401 system that has a cutoff at $2 \mathrm{mV}$ (range 1 to -1 ) and thus we could not be sure of the true MEP amplitude when it exceeded $2 \mathrm{mV}$ (e.g., $2.1 \mathrm{mV}, 4 \mathrm{mV}$, etc.). For this reason, we elected to exclude such MEPs that "maxed out," as we feel that this provides the most accurate version of the MEP dataset. The mean percentage of excluded trials across participants was $5.89 \pm 0.92 \%$, and there was no significant difference in the number of excluded trials for low and high WM load $(t<1)$. Mean peak-to-peak amplitudes of MEPs were calcu- 

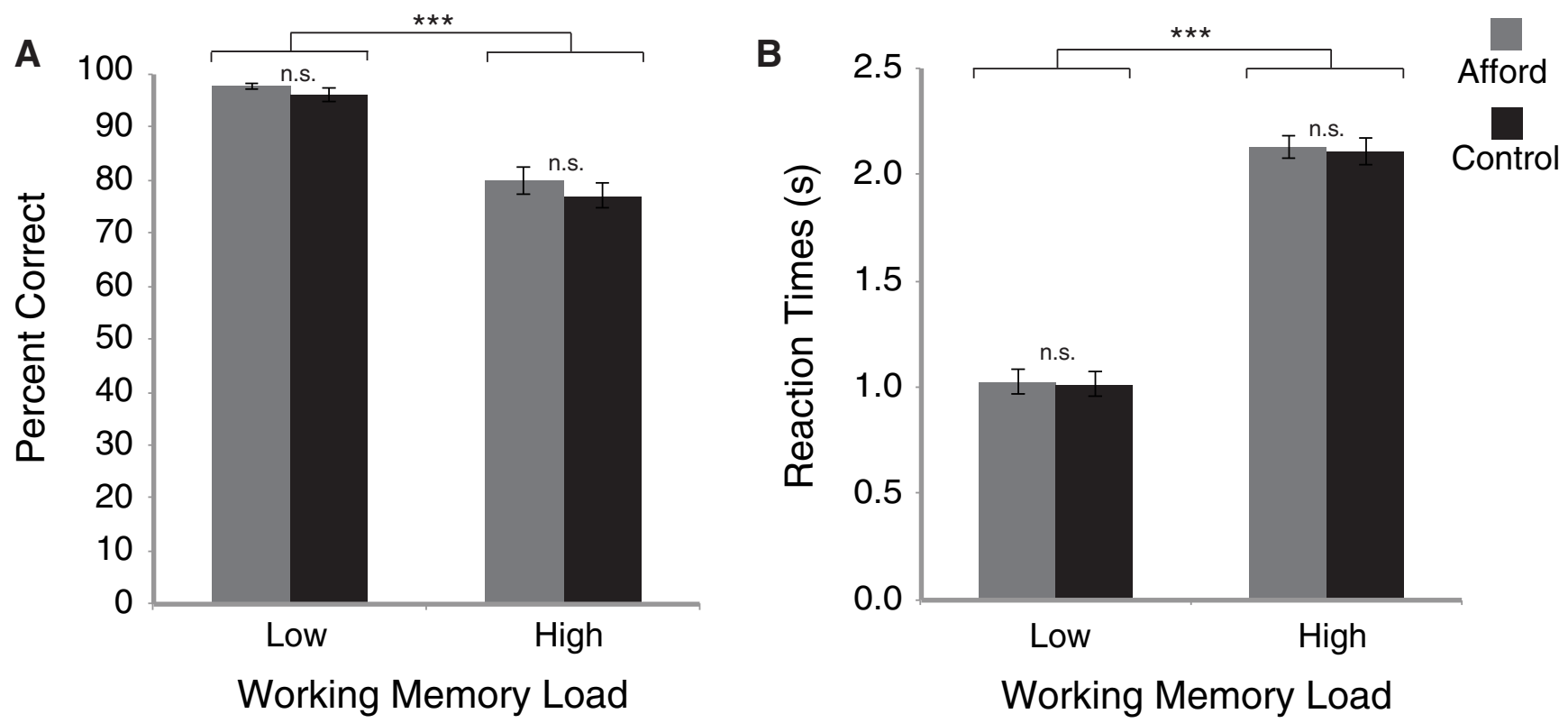

C

\section{Pre-object Frontal Theta}

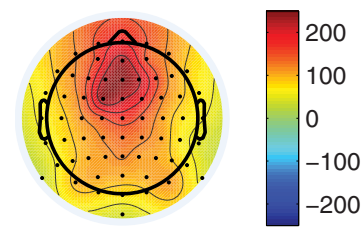

High Load
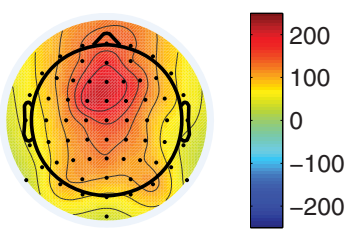

Low Load
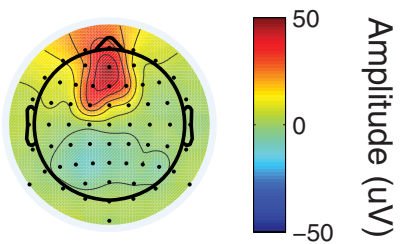

High Load - Low Load

Figure 2. Behavior and pre-object frontal theta. $\boldsymbol{A}$, Percent correct was significantly higher on low versus high load trials. $\boldsymbol{B}$, RTs were significantly shorter on low versus high load trials. $\boldsymbol{C}$, Frontal theta amplitude measured before the onset of the object was significantly greater for high versus low load ( $p<0.05$ ). Together, these results demonstrate that the WM manipulation was effective. Error bars indicate SEM. ${ }^{* * *} p<0.001$. n.S., Not significant.

lated for all conditions. The pulse times of 300 and $500 \mathrm{~ms}$ preceding or following the object were collapsed, as the two pulse times only served to reduce predictability among participants. LICI was calculated for each participant and in each condition using the following formula: $\operatorname{LICI}(\%)=[1-(\mathrm{TP} / \mathrm{NP})] \times 100$, where TP is the median test pulse MEP amplitude and NP is the median nonconditioned pulse MEP amplitude. Thus, 100\% inhibition reflects complete abolition of the TP MEP amplitude whereas $0 \%$ inhibition reflects no effect of the conditioning stimulus (Coxon et al., 2006). LICI values were then entered into a repeatedmeasures ANOVA with factors of Load (high/low) and Time (before/ after). Although affording and control stimuli were used to match Experiment 1's design, the object type was not a factor in the analysis, as the goal was to measure LICI rather than the affordance.

\section{Results}

\section{Experiment 1}

\section{Behavior}

For high load, the average WM letter string length was 8.07 (SD = 0.73 ), and the percentage correct was $80 \pm 2 \%$, closely matching the target percentage correct of $75 \%$. Our load manipulation was effective, as percentage correct for high load was significantly lower than for low load ( $96 \pm 41 \%, t_{(13)}=10.5, p<0.001$; Fig. $2 A)$. Similarly, mean RTs in high load $(2.13 \pm 0.06 \mathrm{~s})$ were sig- nificantly slower than in low load $\left(1.04 \pm 0.06 \mathrm{~s}, t_{(13)}=16.8\right.$, $p<0.001$; Fig. $2 B)$.

\section{Midline frontal theta}

As another validation of WM load, we examined frontal theta amplitude. This was significantly increased in the $750 \mathrm{~ms}$ period before the object (affording or control) for the high compared with low load WM conditions $\left(t_{(13)}=2.81, p=0.01\right.$; Fig. $2 C$ ). This is consistent with previous studies (Gevins et al., 1997; Jensen and Tesche, 2002; Sauseng et al., 2010; Itthipuripat et al., 2013).

\section{$M u E R D$}

$\mathrm{Mu}$ ERD is a standard measure of motor affordance and greater mu ERD has been directly linked to larger MEPs in M1 (Takemi et al., 2013). As a previous mu ERD affordance study only observed the affordance effect in the lower portion of the mu frequency range (Ruther et al., 2014), we analyzed lower $(7-10 \mathrm{~Hz})$ and higher $(10-13 \mathrm{~Hz}) \mathrm{mu}$ frequency bands separately Load (high/low) and Object (affording/control) as factors. 
A

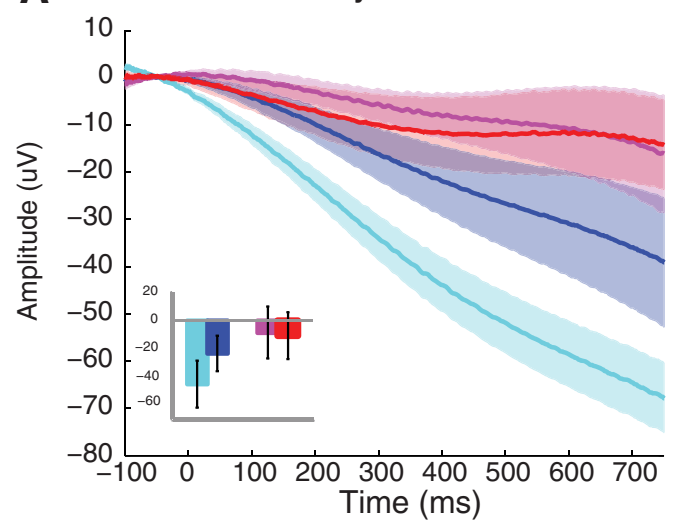

C

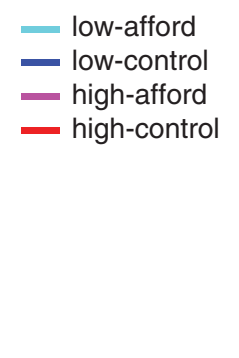

C Centroparietal P300

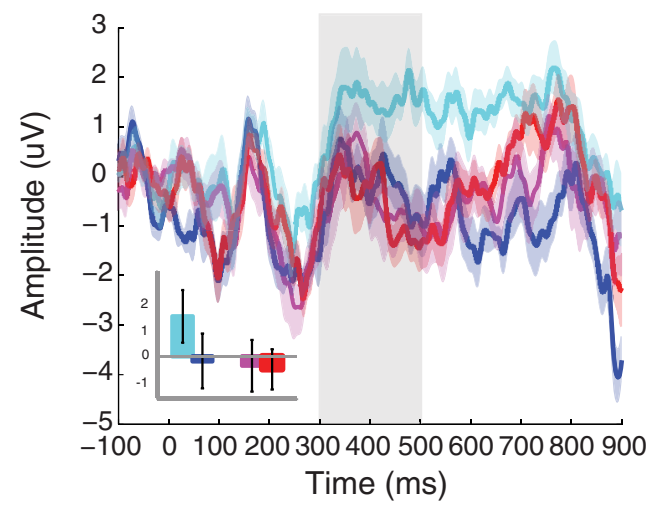

B

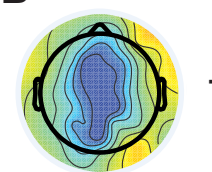

Low load (afford-control)

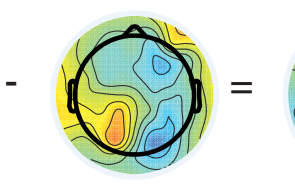

High load

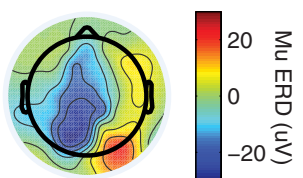

Low - High load

(afford-control)
D

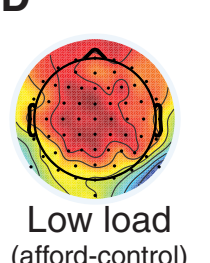

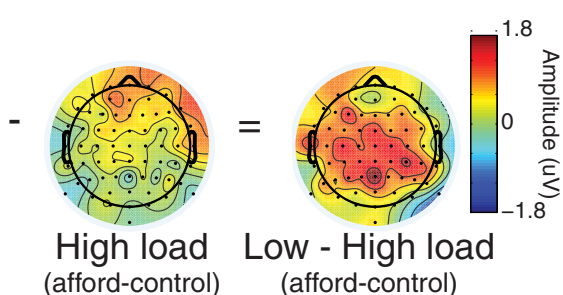

Figure 3. Electrophysiological affordance measures for centroparietal midline electrodes. $\boldsymbol{A}$, For the low load condition, there was significantly greater mu desynchronization (in the $7-10 \mathrm{~Hz}$ range) for the affording versus the control object, demonstrating an affordance effect. There was no difference in mu desynchronization in the high load condition. $\boldsymbol{B}$, The topographic map for the mu desynchronization showed a strong affordance effect over centroparietal electrodes ( $C z, C P z, P z)$ in the low load condition, whereas the topographic map for the high load condition showed no evidence of an affordance effect anywhere in the brain. The interaction between Load and Object was strongest for more posterior regions of the left hemisphere. $\boldsymbol{C}$, For the low load condition, the amplitude of the P300 ERP was significantly greater for the affording object compared with the nonaffording control object. This was consistent with the mu desynchronization results, as was the lack of a difference in P300 amplitude in the high load condition, resulting in a significant interaction. D, The topographic map for the P300 shows a strong affordance effect over centroparietal electrodes in the low load condition, yet no differences in the high load condition.

For the lower mu frequency range $(7-10 \mathrm{~Hz})$, ANOVA showed a significant main effect of $\operatorname{Load}\left(F_{(1,13)}=5.15, p=0.04\right)$, with the low load showing overall greater mu ERD than the high load condition. Moreover, there was a nearly significant Load $X$ Object interaction $\left(F_{(1,13)}=4.5, p=0.054\right)$, whereby mu ERD was diminished under the high WM load (Fig. $3 A, B$ ). Planned $t$ tests showed a significant mu ERD for the affording versus control object in the low load condition $\left(t_{(13)}=2.71, p=0.02\right)$, but not in the high load condition $(t<1)$. Moreover, mu ERD for the affording object was significantly greater for low load compared with high load $\left(t_{(13)}=3.7, p=0.003\right)$, whereas the control object showed no load differences $(t<1)$. We also tested mu ERD in left hemisphere centroparietal electrodes immediately adjacent to the midline $(\mathrm{C} 1, \mathrm{CP} 1$, and $\mathrm{P} 1)$ because all the cups were right handled, and found a significant main effect of Load $\left(F_{(1,13)}=\right.$ $5.82, p=0.03)$, as well as a significant Load $\times$ Object interaction $\left(F_{(1,13)}=5.57, p=0.03\right)$.

For the upper mu frequency range $(10-13 \mathrm{~Hz})$, ANOVA showed no significant main effects or interactions in mu ERD $(F$ values $<1)$. These results are consistent with a previous study that found mu ERD affordance effects in the lower, but not the upper, frequency range (Rüther et al., 2014).

\section{Centroparietal P300}

The centroparietal P300 is another measure of the motor affordance. ANOVA revealed a significant Load $\times$ Object interaction $\left(F_{(1,13)}=6.18, p=0.03\right)$, with higher centroparietal P300 amplitude for the affording versus the control object in the low load condition $\left(t_{(13)}=3.36, p=0.005\right)$, yet no affordance effect in the high load condition $(t<1$ ) (Fig. 3C,D). This is consistent with the lower frequency mu ERD results.

\section{Posterior-occipital P100}

To test whether WM load may have differential effects on early perceptual processing for the affording and control object stimuli, we examined the amplitude modulation of the posterioroccipital P100. The P100 is a suitable ERP component to address this question because the modulation of the P100 has been linked to early sensory gain in visual cortex and early perceptual processing of visual stimuli (Van Voorhis and Hillyard, 1977; Woldorff et al., 1997; Hillyard and Anllo-Vento, 1998; Itthipuripat et al., 2014). ANOVA with factors of Load (high/low), Object (affording/control), and Hemisphere (left/right) revealed a significant main effect of Object $\left(F_{(1,13)}=5.88, p=0.03\right)$, with the affording object showing a higher amplitude than the control object. There was also a significant Object $\times$ Hemisphere interaction $\left(F_{(1,13)}=\right.$ 10.16, $p=0.007$ ). Follow-up ANOVAs that analyzed the two hemispheres separately with Object and Load as factors showed a significant main effect of Object in the left hemisphere $\left(F_{(1,13)}=\right.$ $12.15, p=0.004)$, but not in the right hemisphere $(F<1)$ (Fig. 4$)$ (for a similar result, see Goslin et al., 2012). Notably, left hemisphere electrodes showed significant affording versus control object differences in both low load $\left(t_{(13)}=2.92, p=0.01\right)$ and high load $\left(t_{(13)}=2.28, p=0.04\right)$ conditions. The greater P100 amplitude to the affording object (right-handled cups) occurred because the handle was likely the most salient feature of the cup and therefore showed greater visual processing in the contralateral left hemisphere, resulting in a larger $\mathrm{P} 100$ response. These results are consistent with a prior affordance study (Goslin et al., 2012). Such lateralized early visual processing did not occur when the urn appeared, as no features of the urn were more salient than others. Importantly, neither hemisphere showed a significant 


\section{Posterior-occipital P100}
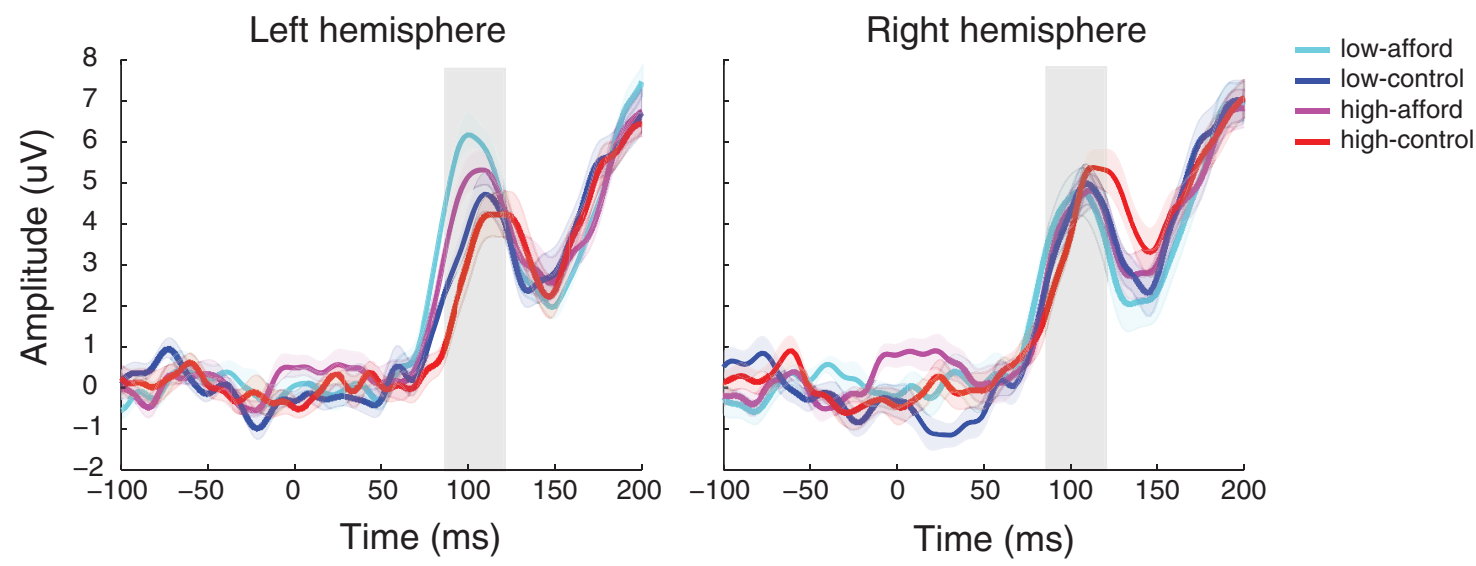

Figure 4. Posterior-occipital P100. While the right hemisphere (right panel) showed no significant effects, the P100 amplitude in the left hemisphere (left panel) was significantly greater for the affording versus the control object during both low load and high load. Notably, there was no difference in P100 amplitude between low and high load, nor was there an interaction between Load and Object. This demonstrates early visual processing for the affording object was selective to the contralateral hemisphere (i.e., the right handled cup in the left hemisphere) and that early sensory perception was not significantly different between high and low WM load.

Load $\times$ Object interaction or a main effect of Load (all $p$ values $>0.18$ ), suggesting that the mu ERD and P300 results were not driven by differences in early perceptual processing across WM loads.

Theta correlations with mu ERD

Above we reported greater theta activity over frontal electrodes for high versus low load before the onset of the object. Notably, lower frequency mu ERD in left hemisphere centroparietal electrodes showed a significant Load $\times$ Object interaction, in which only the low load condition showed an affordance effect (i.e., greater mu ERD for affording vs control object). This suggests that greater engagement of frontal regions (frontal theta prior to the object presentation $[-750$ to 0$]$ ) could relate to the diminished affordance effect (mu ERD after the onset of the affording versus control object) during high load. To test this, each participant's pre-object theta amplitude in the low load was subtracted from the their pre-object theta amplitude in the high load to obtain a participant-specific theta "load effect" value (i.e., a higher number indicates more frontal theta activity in high load compared to low load). To calculate a mu ERD interaction value for each participant, left hemisphere centroparietal mu ERD for the control object was first subtracted from the affording object, yielding a separate affordance value for low and high load. Then, the low load affordance value was subtracted from the high load affordance value to obtain a participant-specific mu ERD "interaction effect" value. Because greater mu ERD is indicated by more negative values, a larger interaction value means that there is a greater affordance effect for low load compared with high load (e.g., if the low load affordance effect $=-50$ [large affordance] and the high load affordance effect $=-5$ [small affordance], then the interaction value would be calculated as $(-5)-$ $(-50)=45$, yielding a large positive interaction value). All values were then $z$-scored, and we correlated the mu ERD interaction effect values against the theta load effect values. There was a significant correlation $\left(r_{(13)}=0.56, p=0.037\right)$, such that participants with greater high load pre-object theta activity (relative to low load) showed a more diminished affordance effect in the high load compared with the low load (Fig. 5). This provides further evidence that greater WM load is associated with a reduced affordance.
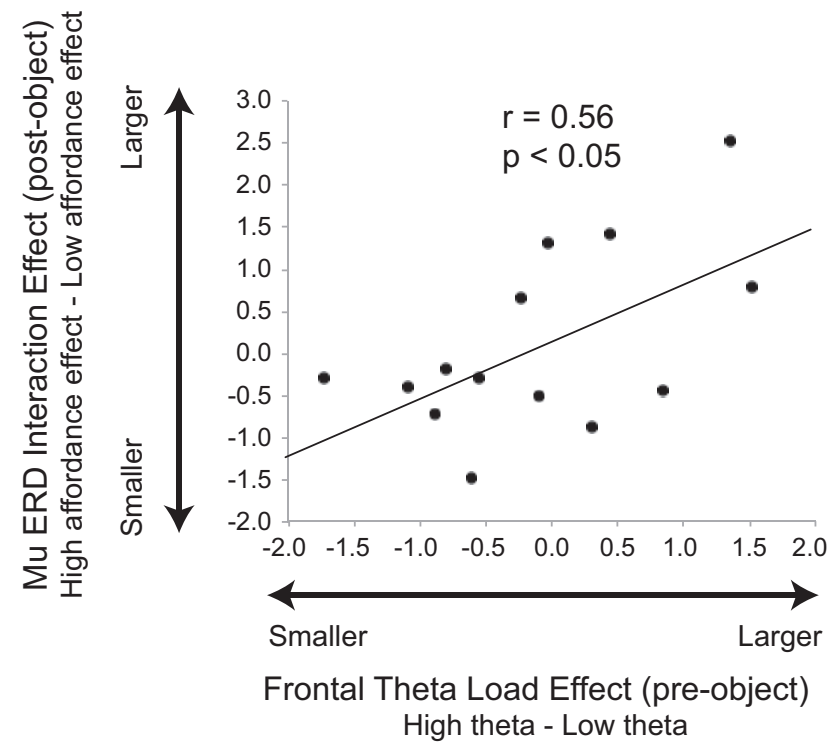

Figure 5. Relationship between frontal theta and mu ERD across participants. The frontal theta load effect represents the engagement of frontal regions during high versus low load. A frontal theta load effect value was calculated for each participant by subtracting the low load pre-object frontal theta amplitude from the high load amplitude. The mu ERD interaction effect represents the degree to which a mu ERD affordance occurred during low load compared with high load in left hemisphere centroparietal electrodes (C1, CP1, P1). A mu ERD interaction effect value was calculated by subtracting the low load mu ERD affordance effect (affording vs control object) from the high load mu ERD affordance effect, yielding an interaction value (see text for further explanation). There was a significant correlation, such that participants with greater high load pre-object theta activity (relative to low load) showed a larger affordance effect for low compared to high load, indicated by a larger interaction value.

\section{Experiment 2}

Experiment 1 showed that increasing WM load reduced the affordance effect. Yet, the mechanism underlying the reduced affordance is still unclear. One possibility is that being in a state of high WM is concomitant with greater sustained inhibitory activity in the motor system (i.e., the motor system is "set" into a suppressed state for the entire duration of the high load trial) (compare Sauseng et al., 2013). As a result, task-irrelevant motor 

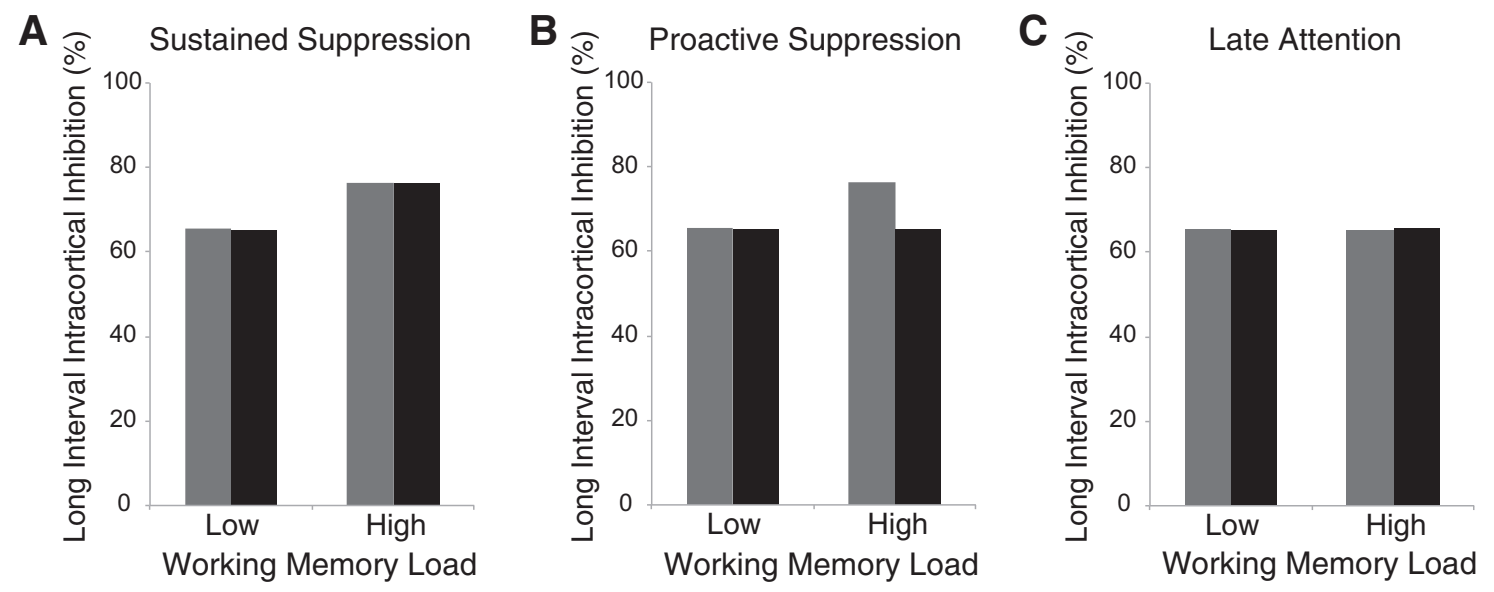

Figure 6. Predictions for different accounts underlying the diminished affordance during high WM load from Experiment 1. $\boldsymbol{A}$, For the sustained suppression account, suppression in M1 occurs when WM resources are engaged. It predicts greater $\mathrm{LICl}$ over M1 for high versus low load both before and after the presentations of the object. $\boldsymbol{B}$, For the proactive suppression account, there is greater motor suppression during high load to reduce the potentially distracting influence of the task-irrelevant object. It predicts greater LICl over $\mathrm{M} 1$ for high versus low load only before the object is presented because it is no longer necessary following the object. $C$, For the late attention account, the diminished affordance during high load is due to reduced attention during the later stages of object processing. It predicts no differences in LICl over M1 for high versus low load.

affordances can no longer potentiate the motor system in the normal fashion, resulting in a diminished affordance effect.

A variant of this account is that, rather than being in a sustained state of suppression, the participant proactively engaged a suppression mechanism just before the anticipated object occurred in an effort to reduce irrelevant, potentially distracting, motor provocations. This would perhaps be particularly important under high load because, according to Lavie's load theory, the potential for distraction is greatest during high WM load due to a reduced capacity to filter the distractors (Lavie et al., 2004).

An entirely different account is that the affordance was reduced under high load because the participant did not attend properly to the object. There are, however, several immediate challenges to this account. First, the P100 results showed higher amplitude for the affording versus control object in the left hemisphere (the contralateral hemisphere to the rightward-facing cup handle) under both low and high load, with no main effect of Load or interaction between Object and Load. As modulation of the P100 has been linked to early perceptual processing of visual stimuli (Van Voorhis and Hillyard, 1977; Woldorff et al., 1997; Hillyard and Anllo-Vento, 1998; Itthipuripat et al., 2014), this result suggests that early attentional processing was not different across loads. Second, several studies found that attentional orienting toward the affording object does not influence the affordance effect (Tucker and Ellis, 2004; Symes et al., 2007; Riggio et al., 2008). In one study (Riggio et al., 2008), the authors used offset stimuli to manipulate the automatic allocation of attention before response selection and execution. Their results showed an affordance effect even when the affording object was not visible during response selection and, more generally, that it occurred independently of the amount of attentional orienting. This has led researchers to characterize affordances as motor potentiations that emerge quickly (i.e., within $150 \mathrm{~ms}$ ) and somewhat automatically (Tucker and Ellis, 2004; Symes et al., 2007; Sumner and Husain, 2008; Franca et al., 2012; Goslin et al., 2012). Notwithstanding these points, we could not rule out the possibility that later attentional processing of the objects (e.g., >150 ms after object onset) was reduced during high load, resulting in a diminished affordance effect.

We now aimed to disambiguate the above-mentioned possible accounts of the diminished affordance. Because the ISI period before the cup was variable and relatively long $(0.75-3$ s), both of the "suppression" accounts above predict that the suppression would be sustained over a time period of several seconds. We therefore measured LICI over M1 because LICI is generally associated with a more tonic form of inhibition, thought to reflect the slower $\mathrm{GABA}_{\mathrm{B}}$ receptor signaling (Kohl and Paulsen, 2010). On the sustained suppression account, the motor system (perhaps primary motor cortex) is "set" into a suppressed state throughout the high WM load trial (before and after the object); on the proactive suppression account, the motor system is "set" into a suppressed state only before the object; and on the attention account, the motor system has nothing to do with the reduced affordance.

TMS pulses were delivered both before and after the object presentation to examine whether any differences in LICI would be present only before the object onset or sustained throughout the WM retention interval. Given this design, each account makes distinct predictions (Fig. 6). If the diminished affordance observed in Experiment 1 is due to increased sustained suppressive activity while in a state of high WM, then this predicts greater LICI for high versus low load through the WM retention interval (i.e., a main effect of Load; Fig. 6A); if it is due to increased suppressive activity that proactively prevents the task-irrelevant affordance to reduce potential distraction, then this predicts greater LICI for high versus low load before, but not after, the object (i.e., an interaction between Load and Time; Fig. 6B); if the diminished affordance is due to reduced late attentional processing of the objects during high load, then this predicts no difference in LICI at M1 (i.e., no main effects or interactions; Fig. 6C).

\section{Behavior}

The behavioral results for Experiment 2 largely resembled those from Experiment 1. For high load, the average WM letter string length was $8.44(\mathrm{SD}=0.73)$ and the percentage correct was $78 \pm$ 


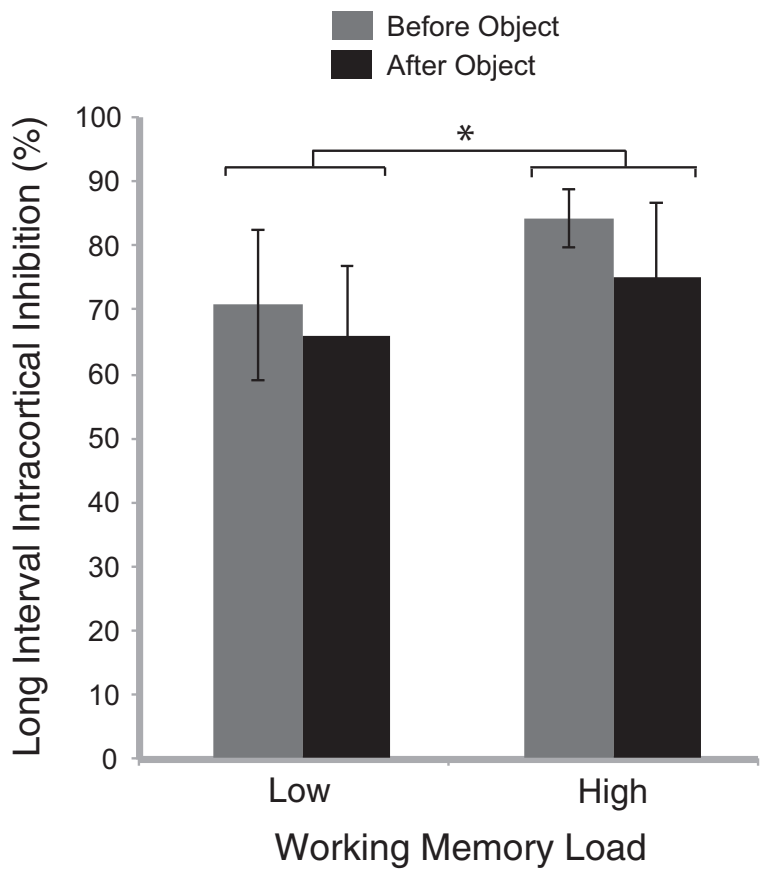

Figure 7. Experiment 2 results. LICI over M1 was greater for high versus low load. This supports the sustained suppression account for the diminished affordance effect during high load, in which greater WM engagement leads to a concomitant increase in inhibitory activity over motor regions. LICl was calculated using the following: LICI (\%) $=[1-($ TP/NP) $] \times 100$, where TP is the test pulse and NP is the nonconditioned pulse. Error bars indicate SEM. ${ }^{*} p<0.05$.

Table 1. Mean MEP amplitudes across participants for each condition ${ }^{a}$

\begin{tabular}{llllll}
\hline & Pre & & & Post & \\
\cline { 2 - 3 } \cline { 6 - 7 } & NP & TP & & NP & TP \\
\hline Low load & $0.418(0.14)$ & $0.103(0.13)$ & & $0.408(0.17)$ & $0.104(0.11)$ \\
High load & $0.618(0.23)$ & $0.092(0.11)$ & & $0.540(0.16)$ & $0.096(0.13)$ \\
\hline
\end{tabular}

${ }^{a}$ Data are given as $\mathrm{mV}:$ mean (SD).

$2 \%$ ), closely matching the target percentage correct of $75 \%$. The load manipulation was successful, as percentage correct for high load was significantly lower than in low load $98 \pm 0.25 \%$; $t_{(15)}=$ $11.6, p<0.001)$, and mean RTs in high load $(2.39 \pm 0.06 \mathrm{~s})$ were significantly slower than in low load $\left(1.04 \pm 0.04 \mathrm{~s} ; t_{(15)}=22.7\right.$, $p<0.001)$. There were no significant differences for percentage correct or RTs when comparing affording versus control trials (all $p$ values $>0.26$ ).

\section{LICI}

For the TMS analysis, ANOVA with the factors of Load (high/ low) and Time (before/after the object) and the dependent measure of LICI showed a significant main effect of Load. Specifically, there was greater LICI for high $(79.6 \%$ inhibition) compared with low $(68.3 \%$ inhibition $)$ WM load $\left(F_{(15)}=5.34, p=0.036\right.$; Fig. 7). There was also a marginally significant main effect of Time $\left(F_{(15)}=4.22, p=0.058\right)$, such that LICI was generally greater before object onset $(77.5 \%$ inhibition) compared with after $(70.4 \%$ inhibition). Notably, there was not a significant Load $\times$ Time interaction $(F<1)$. As can be seen from Figure 6, these results support the sustained suppression account. The mean NP and TP data for both time periods are presented in Table 1. An increase in the NP amplitude during high load is contributing to the difference in LICI, which is not surprising because high load likely elicits greater physiological responses that can influence the MEP (e.g., stress and arousal). Despite the NP amplitude increase under high load, the TP in the high load condition remained low, indicating an inhibitory influence in M1 during high load.

\section{Discussion}

We tested whether WM load influences motor potentiation from affording objects. We predicted that high load would increase the motor affordance, which was measured via mu ERD and the P300 ERP component over centroparietal electrodes. Under low load, there was a motor affordance: lowfrequency $\mathrm{mu}$ ERD was greater for affording versus nonaffording control objects, consistent with previous research (Rüther et al., 2014). Contrary to our prediction, Experiment 1 showed that, for both EEG neural measures (mu ERD and P300 amplitude), the affordance effect was present during low, but not high, WM load. A subsequent exploratory analysis indicated that individuals with greater WM-related neural activity (measured via pre-object frontal theta activity) showed a larger interaction effect (measured via mu ERD activity) in high versus low load. Note that a larger interaction value indicates a larger affordance effect for low compared to high load. This shows that the increase in frontal theta activity during high WM load is related to reductions in taskirrelevant motor provocations. We explored the mechanism responsible for the diminished affordance in Experiment 2 using ppTMS to measure long-interval cortical inhibition (LICI) over M1 during high load versus low load. Results showed greater LICI in M1 during high compared low load, and that this was not dependent on the timing of the LICI measurement (before versus after the object). This suggests that the reduced affordance under high load in Experiment 1 was due to increased sustained suppression of M1. These findings provide new insights into the interaction between WM and the inhibitory state of M1 and also speak to the extent to which affordances are or are not automatic.

\section{Implications}

The results across the two studies show that high WM load reduces the motor affordance and increases intracortical inhibition in M1. Putting these together, we suppose that high load "sets" the motor system into a suppressed state; and, because of this, the incipient affordance cannot get expressed in the same way. We suppose that greater intracortical inhibition during high load prevents mu desynchronization, which is thought to reflect a reduction of intracortical inhibition and increased pyramidal neuron firing in M1 (Leocani et al., 2001; Takemi et al., 2013; for a different paradigm, compare Hummel et al., 2002).

Although it is intuitively true that being in a concentrated state prevents processing of incoming sensory information, there are exceptions to this (e.g., Lavie's demonstrations that there is more distractibility under high WM load; Lavie et al., 2004). Regardless, here we specifically show that being under high WM load has effects on M1, and we suppose these effects mitigate a motor affordance (which, to our knowledge, is a novel finding). This speaks to a second implication of our study, which is the automaticity of motor affordances. Many studies have argued that affordances are automatic, as they can occur even in the absence of focused attention on the object (Leocani et al., 2001; Riggio et al., 2008; McBride et al., 2012; Takemi et al., 2013). However, the current results indicate that whether an affordance is expressed may also rely on an indi- 
viduals' current cognitive state (i.e., high vs low WM load). This suggests that subthreshold motor provocations do not necessarily occur all the time. Rather, the strength and potential influence of such provocations depend on the excitatory/ inhibitory state of the motor system at the time when the object is viewed (Knight et al., 1999). Notably, while in the current study we observed this interaction using motor affordances, it is possible that the same principles apply for other types of motor provocations, including learned stimulus-response pairings (e.g., in the Flanker or Stroop tasks) and motivationally triggered provocations (Freeman et al., 2014; Freeman et al., 2015).

A third implication of our results concerns individuals with attention deficit hyperactivity disorder (ADHD), who have substantial WM problems (Rapport et al., 2008; Raiker et al., 2012), reduced intracortical inhibition (Gilbert et al., 2004, 2011; Buchmann et al., 2007), increased motor hyperactivity (at least for some forms of ADHD) and poor specific (Lijffijt et al., 2005) and general (Barkley, 1997) response inhibitory control abilities. In light of the current study, which links increased WM load to increased intracorical inhibition at M1, one might wonder whether there is a similar relation in the case of ADHD. It is possible that deficient WM and reduced intracortical inhibition at M1 in ADHD are related and that this results in increased motor provocation and distractibility from task-irrelevant objects.

\section{Limitations and future questions}

This study has some limitations. First, we deliberately used a task that did not require button presses/responses for the affording/control object (instead, we operationalized the affordance physiologically alone). Although this obviated any dual task effects, it meant that we had no behavioral index of the affordance, thus limiting our ability to link neural and behavioral measures. Second, in Experiment 2, there was no physiological index of affordance; thus, we have to infer that an affordance did occur. Future studies could use combined EEG and ppTMS to try to directly relate changes in intracortical inhibition with changes in the affordance in the same experiment. Alternatively, single-pulse TMS could be used at specific time points after the affordance, in the same experiment as ppTMS to index LICI. Third, we only measured motor excitability from the right index finger muscle, which was behaviorally relevant to the affording object (right-handled cup). It is therefore unclear whether we would have observed increased LICI across all muscles in the motor system, or whether the effect was more restricted to behaviorally relevant muscles. Fourth, although we sampled pulse times before and after the object, we cannot know whether increased LICI was truly sustained across the entire WM delay period or whether it was a more phasic process that occurred near the time of object presentation. Finally, because we did not collect control LICI data in a resting state, we cannot rule out the possibility that there was less inhibition in the low WM condition compared with rest and high load. However, we believe this is unlikely for two reasons. First, the targeted inhibition during the thresholding procedure (when the participant was at rest) was $50 \%$, which is far below the $70 \%$ inhibition we observed during low WM load. Second, while our LICI results (increased inhibition for high WM, which likely corresponded to a mitigation of the affordance in Experiment 1) are consistent with a sustained-suppression-under-high-WM account, we cannot think of any theory compatible with the pattern of results where there is less inhibition under low load compared with rest and high load.

In conclusion, whereas we predicted that being under higher WM load would deplete frontal resources and enhance the affordance effect, we found that the affordance effect was instead diminished under high load. In Experiment 2, we found increased long-interval cortical inhibition over M1 during high load, suggesting that a sustained suppression of motor activity over M1 prevented the affordance from being generated. These results suggest a close connection between WM-related neural activity and the balance of excitatory and inhibitory activity in the motor cortex. They also provide insights into when and how taskirrelevant motor provocations can be prevented from influencing the motor system. Importantly, these insights may help provide a link between well-known behavioral and brain-related dysfunctions in ADHD.

\section{Notes}

Raw data for this article are available at https://github.com/scottfreeman/Freeman-Itthipuripat-and-Aron. This repository contains behavioral and EEG data for Experiment 1 and behavioral and TMS data for Experiment 2. Supplemental material for this article is available at the same URL. This includes Excel files with raw data and also unpublished observations that have not been peer-reviewed.

\section{References}

Archibald SJ, Mateer CA, Kerns KA (2001) Utilization behavior: clinical manifestations and neurological mechanisms. Neuropsychol Rev 11: 117-130. CrossRef Medline

Arroyo S, Lesser RP, Gordon B, Uematsu S, Jackson D, Webber R (1993) Functional significance of the mu rhythm of human cortex: an electrophysiologic study with subdural electrodes. Electroencephalogr Clin $\mathrm{Neu}-$ rophysiol 87:76-87. CrossRef Medline

Barkley RA (1997) Behavioral inhibition, sustained attention, and executive functions: constructing a unifying theory of ADHD. Psychol Bull 121: 65-94. CrossRef Medline

Besnard J, Allain P, Aubin G, Osiurak F, Chauviré V, Etcharry-Bouyx F, Le Gall D (2010) Utilization behavior: clinical and theoretical approaches. J Int Neuropsychol Soc 16:453-462. CrossRef Medline

Buccino G, Sato M, Cattaneo L, Rodà F, Riggio L (2009) Broken affordances, broken objects: a TMS study. Neuropsychologia 47:3074-3078. CrossRef Medline

Buchmann J, Gierow W, Weber S, Hoeppner J, Klauer T, Benecke R, Haessler F, Wolters A (2007) Restoration of disturbed intracortical motor inhibition and facilitation in attention deficit hyperactivity disorder children by methylphenidate. Biol Psychiatry 62:963-969. CrossRef Medline

Chao LL, Martin A (2000) Representation of manipulable man-made objects in the dorsal stream. Neuroimage 12:478-484. CrossRef Medline

Chen R, Lozano AM, Ashby P (1999) Mechanism of the silent period following transcranial magnetic stimulation: evidence from epidural recordings. Exp Brain Res 128:539-542. CrossRef Medline

Chu J, Gunraj C, Chen R (2008) Possible differences between the time courses of presynaptic and postsynaptic GABAB mediated inhibition in the human motor cortex. Exp Brain Res 184:571-577. CrossRef Medline

Coxon JP, Stinear CM, Byblow WD (2006) Intracortical inhibition during volitional inhibition of prepared action. J Neurophysiol 95:3371-3383. CrossRef Medline

Delorme A, Makeig S (2004) EEGLAB: an open source toolbox for analysis of single-trial EEG dynamics. J Neurosci Methods 134:9-21.

Ellis R, Tucker M (2000) Micro-affordance: the potentiation of components of action by seen objects. Br J Psychol 91:451-471. CrossRef Medline

Fischer MH, Dahl CD (2007) The time course of visuo-motor affordances. Exp brain Res 176:519-524. CrossRef Medline

Franca M, Turella L, Canto R, Brunelli N, Allione L, Andreasi NG, Desantis M, Marzoli D, Fadiga L (2012) Corticospinal facilitation during observation of graspable objects: a transcranial magnetic stimulation study. PLoS One 7:1-9. CrossRef Medline

Freeman SM, Razhas I, Aron AR (2014) Top-down response suppression 
mitigates action tendencies triggered by a motivating stimulus. Curr Biol 24:212-216. CrossRef Medline

Freeman SM, Alvernaz D, Tonnesen A, Linderman D, Aron AR (2015) Suppressing a motivationally-triggered action tendency engages a response control mechanism that prevents future provocation. Neuropsychologia 68:218-231. CrossRef Medline

Gevins A, Smith ME, McEvoy L, Yu D (1997) High-resolution EEG mapping of cortical activation related to working memory: effects of task difficulty, type of processing, and practice. Cereb Cortex 7:374-385. CrossRef Medline

Gibson J (1979) The ecological approach to visual perception. Boston, MA: Houghton-Mifflin.

Gilbert DL, Bansal AS, Sethuraman G, Sallee FR, Zhang J, Lipps T, Wassermann EM (2004) Association of cortical disinhibition with tic, ADHD, and OCD severity in Tourette syndrome. Mov Disord 19:416-425. CrossRef Medline

Gilbert DL, Isaacs KM, Augusta M, MacNeil LK, Mostofsky SH (2011) Motor cortex inhibition: a marker of ADHD behavior and motor development in children. Neurology 76:615-621. CrossRef Medline

Goslin J, Dixon T, Fischer MH, Cangelosi A, Ellis R (2012) Embodiment in vision and action. Psychol Sci 23:152-157. CrossRef Medline

Grafton ST, Fadiga L, Arbib MA, Rizzolatti G (1997) Premotor cortex activation during observation and naming of familiar tools. Neuroimage 6:231-236. CrossRef Medline

Handy TC, Grafton ST, Shroff NM, Ketay S, Gazzaniga MS (2003) Graspable objects grab attention when the potential for action is recognized. Nat Neurosci 6:421-427. CrossRef Medline

Hillyard SA, Anllo-Vento L (1998) Event-related brain potentials in the study of visual. Proc Natl Acad Sci U S A 95:781-787. CrossRef Medline

Hsieh L-T, Ranganath C (2014) Frontal midline theta oscillations during working memory maintenance and episodic encoding and retrieval. NeuroImage 85:721-729.

Hummel F, Andres F, Altenmüller E, Dichgans J, Gerloff C (2002) Inhibitory control of acquired motor programmes in the human brain. Brain 125:404-420. CrossRef Medline

Itthipuripat S, Wessel JR, Aron AR (2013) Frontal theta is a signature of successful working memory manipulation. Exp Brain Res 224:255-262. CrossRef Medline

Itthipuripat S, Ester EF, Deering S, Serences JT (2014) Sensory gain outperforms efficient readout mechanisms in predicting attention-related improvements in behavior. J Neurosci 34:13384-13398. CrossRef Medline

Jensen O, Tesche CD (2002) Frontal theta activity in humans increases with memory load in a working memory task. Eur J Neurosci 15:1395-1399. CrossRef Medline

Kim SY, Kim MS, Chun MM (2005) Concurrent working memory load can reduce distraction. Proc Natl Acad Sci U S A 102:16524-16529. CrossRef Medline

Knight RT, Staines WR, Swick D, Chao LL (1999) Prefrontal cortex regulates inhibition and excitation in distributed neural networks. Acta Psychol (Amst) 101:159-178. CrossRef Medline

Kohl MM, Paulsen O (2010) The roles of GABAB receptors in cortical network activity. Adv Pharmacol 58:205-229. CrossRef Medline

Kumar S, Riddoch MJ, Humphreys G (2013) Mu rhythm desynchronization reveals motoric influences of hand action on object recognition. Front Hum Neurosci 7:1-9. CrossRef Medline

Lavie N, Hirst A, de Fockert JW, Viding E (2004) Load theory of selective attention and cognitive control. J Exp Psychol Gen 133:339-354. CrossRef Medline

Leocani L, Toro C, Zhuang P, Gerloff C, Hallett M (2001) Event-related desynchronization in reaction time paradigms: a comparison with eventrelated potentials and corticospinal excitability. Clin Neurophysiol 112: 923-930. CrossRef Medline

Lhermitte F (1983) "Utilization behaviour" and its relation to lesions of the frontal lobes. Brain 106:237-255. CrossRef Medline

Lijffijt M, Kenemans JL, Verbaten MN, van Engeland H (2005) A metaanalytic review of stopping performance in attention-deficit/hyperactivity disorder: deficient inhibitory motor control? J Abnorm Psychol 114: 216-222. CrossRef Medline

Luck SJ (2005) An Introduction to the Event-Related Potential Technique. Cambridge, MA: MIT Press.

Makeig S, Bell AJ, Jung T-P, Sejnowski TJ (1996) Independent component analysis of electroencephalographic data. Advances Neural Info Processing Sys 8:145-151.
McBride J, Boy F, Husain M, Sumner P (2012) Automatic motor activation in the executive control of action. Front Hum Neurosci 6:82. CrossRef Medline

McBride J, Sumner P, Jackson SR, Bajaj N, Husain M (2013) Exaggerated object affordance and absent automatic inhibition in alien hand syndrome. Cortex 49:2040-2054. CrossRef Medline

McDonnell MN, Orekhov Y, Ziemann U (2006) The role of GABA(B) receptors in intracortical inhibition in the human motor cortex. Exp brain Res 173:86-93. CrossRef Medline

McFarland DJ, Miner LA, Vaughan TM, Wolpaw JR (2000) Mu and beta rhythm topographies during motor imagery and actual movements. Brain Topogr 12:177-186. CrossRef Medline

Mitchell JP, Macrae CN, Gilchrist ID (2002) Working memory and the suppression of reflexive saccades. J Cogn Neurosci 14:95-103. CrossRef Medline

Mizuhara H, Yamaguchi Y (2011) Neuronal ensemble for visual working memory via interplay of slow and fast oscillations. Eur J Neurosci 33: 1925-1934. CrossRef Medline

Muthukumaraswamy SD, Johnson BW, McNair NA (2004) Mu rhythm modulation during observation of an object-directed grasp. Brain Res Cogn Brain Res 19:195-201 CrossRef Medline

Nakamura H, Kitagawa H, Kawaguchi Y, Tsuji H (1997) Intracortical facilitation and inhibition after transcranial magnetic stimulation in conscioushliumans. J Physiol 498:817-823. CrossRef Medline

Onton J, Delorme A, Makeig S (2005) Frontal midline EEG dynamics during working memory. Neuroimage 27:341-356. CrossRef Medline

Owen AM, McMillan KM, Laird AR, Bullmore E (2005) N-back working memory paradigm: a meta-analysis of normative functional neuroimaging studies. Hum Brain Mapp 25:46-59. CrossRef Medline

Pesonen M, Hämäläinen H, Krause CM (2007) Brain oscillatory 4-30 Hz responses during a visual n-back memory task with varying memory load. Brain Res 1138:171-177. CrossRef Medline

Pfurtscheller G (2003) Induced oscillations in the alpha band: functional meaning. Epilepsia 44[Suppl 12]:2-8. CrossRef Medline

Pfurtscheller G, Aranibar A (1979) Evaluation of event-related desynchronization (ERD) preceding and following voluntary self-paced movement. Electroencephalogr Clin Neurophysiol 46:138-146. CrossRef Medline

Pfurtscheller G, Lopes da Silva FH (1999) Event-related EEG/MEG synchronization and desynchronization: basic principles. Clin Neurophysiol 110:1842-1857. CrossRef Medline

Pfurtscheller G, Neuper C (1997) Motor imagery activates primary sensorimotor area in humans. Neurosci Lett 239:65-68. CrossRef Medline

Pfurtscheller G, Brunner C, Schlögl A, Lopes da Silva FH (2006) Mu rhythm (de)synchronization and EEG single-trial classification of different motor imagery tasks. Neuroimage 31:153-159. CrossRef Medline

Proverbio AM (2012) Tool perception suppresses 10-12 Hz $\mu$ rhythm of EEG over the somatosensory area. Biol Psychol 91:1-7. CrossRef Medline

Proverbio AM, Adorni R, D'Aniello GE (2011) $250 \mathrm{~ms}$ to code for action affordance during observation of manipulable objects. Neuropsychologia 49:2711-2717. CrossRef Medline

Raiker JS, Rapport MD, Kofler MJ, Sarver DE (2012) Objectively-measured impulsivity and attention-deficit/hyperactivity disorder (ADHD): testing competing predictions from the working memory and behavioral inhibition models of ADHD. J Abnorm Child Psychol 40:699-713. CrossRef Medline

Rapport MD, Alderson RM, Kofler MJ, Sarver DE, Bolden J, Sims V (2008) Working memory deficits in boys with attention-deficit/hyperactivity disorder (ADHD): the contribution of central executive and subsystem processes. J Abnorm Child Psychol 36:825-837. CrossRef Medline

Riggio L, Iani C, Gherri E, Benatti F, Rubichi S, Nicoletti R (2008) The role of attention in the occurrence of the affordance effect. Acta Psychol (Amst) 127:449-458. CrossRef Medline

Righi S, Orlando V, Marzi T (2014) Attractiveness and affordance shape tools neural coding: Insight from ERPs. Int J Psychophysiol 91:240-253. CrossRef Medline

Rüther NN, Brown EC, Klepp A, Bellebaum C (2014) Observed manipulation of novel tools leads to mu rhythm suppression over sensory-motor cortices. Behav Brain Res 261:328-335. CrossRef Medline

Sauseng P, Gerloff C, Hummel FC (2013) Two brakes are better than one: the neural bases of inhibitory control of motor memory traces. Neuroimage 65:52-58. CrossRef Medline

Schaefer M, Heinze HJ, Galazky I (2010) Alien hand syndrome: neural cor- 
relates of movements without conscious will. PLoS One 5:e15010. CrossRef Medline

Shallice T, Burgess PW, Schon F, Baxter DM (1989) The origins of utilization behaviour. Brain 112:1587-1598. CrossRef Medline

Sumner P, Husain M (2008) At the edge of consciousness: automatic motor activation and voluntary control. Neuroscientist 14:474-486. CrossRef Medline

Symes E, Ellis R, Tucker M (2007) Visual object affordances: object orientation. Acta Psychol (Amst) 124:238-255. CrossRef Medline

Takemi M, Masakado Y, Liu M, Ushiba J (2013) Event-related desynchronization reflects downregulation of intracortical inhibition in human primary motor cortex. J Neurophysiol 110:1158-1166. CrossRef Medline

Tucker M, Ellis R (1998) On the relations between seen objects and compo- nents of potential actions. J Exp Psychol Hum Percept Perform 24: 830-846. CrossRef Medline

Tucker M, Ellis R (2004) Action priming by briefly presented objects. Acta Psychol (Amst) 116:185-203. CrossRef Medline

Van Voorhis S, Hillyard S (1977) Visual evoked potentials and selective attention to points in space. Percept Psychophys 22:54-62. CrossRef

Wang HC, Lees AJ, Brown P (1999) Impairment of EEG desynchronisation before and during movement and its relation to bradykinesia in Parkinson's disease. J Neurol Neurosurg Psychiatry 66:442-446. CrossRef Medline

Woldorff MG, Fox PT, Matzke M, Lancaster JL, Veeraswamy S, Zamarripa F, Seabolt M, Glass T, Gao JH, Martin CC, Jerabek P (1997) Retinotopic organization of early visual spatial attention effects as revealed by PET and ERPs. Hum Brain Mapp 5:280-286. CrossRef Medline 